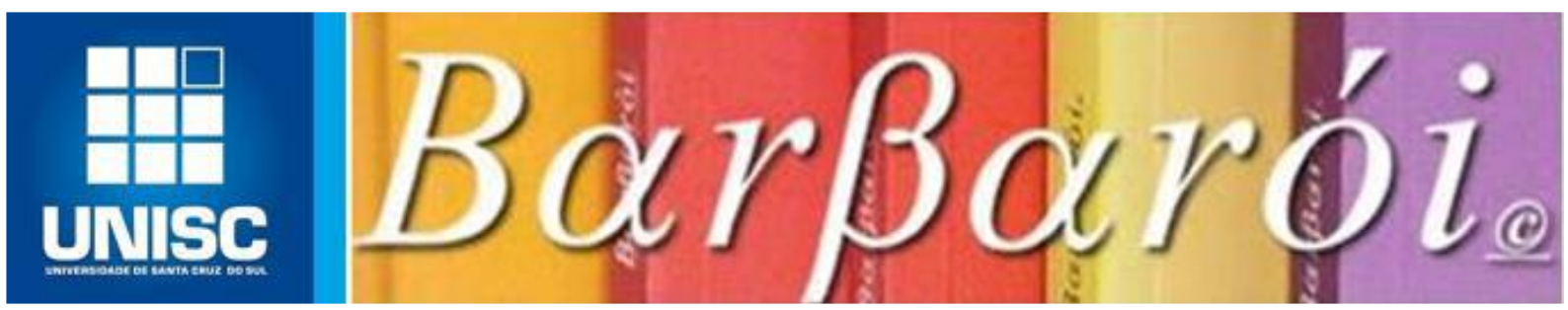

\title{
REMINISCÊNCIAS DA TEORIA TRADICIONAL DO CURRÍCULO: UM MAPEAMENTO DA CONJUNTURA NORTE-AMERICANA SOBRE O INAUGURAR DO SÉCULO XX
}

\author{
DOI: http://dx.doi.org/10.17058/barbaroi.v0i0.14766

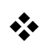

Júlio César Apolinário Maia

Universidade Federal de Jataí - UFJ - Brasil

$*$

\begin{abstract}
Resumo
O presente estudo caracteriza-se como uma pesquisa bibliográfica objetivada a compreender o sentido dado à dinâmica curricular a partir das nuances sócio-político-culturais que se protagonizaram nos Estados Unidos da América durante o primeiro meado do século passado. Configura-se em cinco tópicos consequentes, a partir de um espectro histórico, que discorrem desde o processo de institucionalização da educação em massa, fomentador do surgimento da Teoria Curricular Tradicional (primórdios do século passado), até o momento de crise da proposta curricular de Tyler (meados do século XX). Também é alvo de especulação deste estudo, no decorrer do trajeto histórico considerado, evidenciar as contribuições de Dewey e Bobbit frente à Teoria Tradicional do Currículo. O esforço de síntese paira sobre o desfalecimento desta perspectiva curricular frente à necessidade humana pela reconfiguração do abarrotado cenário educacional norte-americano.
\end{abstract}

Palavras-chave: História do currículo; teoria curricular; pedagogia tradicional.

\section{Introdução}

Ao sustentar uma leitura acerca da força de expressão advinda do currículo em prol de um determinado sentido educacional, Silva (2006) auxilia na compreensão de como este instrumento se solidifica perante diferentes projetos sociais e culturais ao longo da história. Tal entendimento depositado sobre o currículo, qual constructo de um determinado momento histórico, possibilita-o ser compreendido enquanto modelável, isto é, expressão educacional que teoricamente se materializa sobre um plano de fundo inconstantemente abarrotado por novas contribuições (fillosóficas, sociológicas, psicológicas, antropológicas etc.) capacitadas a diferentes (e até divergentes) intuitos. 
Silva (2004), ao retratar três diferentes momentos históricos, considera existir, em igual número, possibilidades de teorias do currículo a serem destacadas: i) as teorias tradicionais, demarcadas por um momento germe dos estudos acerca de um modelo organizacional para as finalidades educacionais características às primícias do século $\mathrm{XX}$; ii) as teorias críticas, capacitadas ao deslocamento das finalidades educacionais, anteriormente compreendidas em sua forma burocrática e mecânica, para uma nova perspectiva de conceitos relativos às teorias sociais vigentes à época e; iii) teorias pós-críticas, essencialmente conceituadas a partir das diferentes perspectivas de coexistência cultural.

Pressupor que o currículo é caracterizado pelo modelo de sociedade interpretado como necessário para que determinados condicionantes sócio-político-culturais vigorem, proporciona ao presente estudo projetar seu objetivo central, qual seja: compreender o sentido dado à dinâmica curricular a partir das nuances sócio-político-culturais que pairaram sobre os Estados Unidos da América (EUA) durante o primeiro meado do século XX. Este recorte se vincula ao aparato histórico que subsidia a perspectiva curricular tradicional, objeto de estudo desta pesquisa.

Porquanto, ao que tange os instrumentos e materiais relacionados aos procedimentos de pesquisa adotados por este estudo, destacam-se documentos, fontes literárias, artigos científicos e textos, isto é, respaldos científicos capacitados à apresentação de uma resposta inicial ao problema da pesquisa, qual seja: qual o sentido do currículo na altura do primeiro meado do século XX em solo norte-americano? Assim faz-se jus, como bem elucidam Lima e Mioto (2007), à tipologia por delineamento concebida a partir da pesquisa bibliográfica.

\section{Onde tudo começou: o efeito propulsor da virada do século $\mathrm{XX}$ à teoria tradicional do currículo}

Merece destaque, ao que concernem as teorias tradicionais do currículo, o processo de institucionalização da educação em massa que se exibe ao contexto norte americano durante a incidência do século XX. Silva (2004), possibilitando compreender o aparato histórico que subsidia tal perspectiva curricular, caracteriza este episódio a partir de alguns condicionantes: i) o estabelecimento de um sistema educacional como dever de um poderio estatal disciplinado; ii) a "cientificização", cada vez mais enraizada, acerca da educação; iii) o alto alcance que a escolarização atingia diante de frações populacionais cada vez mais amplas; iv) a intensificação do sentido acerca de uma identidade nacional, diante do processo imigratório e; v) a industrialização e a urbanização enquanto reflexo de um modelo econômico emergente.

Barbarói, Santa Cruz do Sul, n. 56, p.<282-294>,jan./jun. 2020 
Tal processo imigratório, durante a transição entre os séculos XIX e XX, se apresenta em função do imenso crescimento do jornalismo popular norte-americano, do estrondoso avanço das vias férreas nos EUA e dos almejos esperançosos sobre íntegras condições de vida por uma quota considerável de imigrantes que se instalavam naquele ambiente.

Com relação à tal crescente, torna-se fundamental o destaque de movimentos que chamariam atenção às recém-nascidas vertentes curriculares tradicionais: i) teoria da evolução de Charles Darwin; ii) teoria da relatividade de Albert Eistein; iii) o Q. I. de Alfred Binet e; iv) o movimento da eugenia ${ }^{1}$ de Francis Galton.

A perspectiva tradicionalista de currículo, dentro desta série de condicionantes, surge enquanto uma tendência que busca analisar e conceber eficientes maneiras para o fomento à perpetuação do quadro hegemônico em que se postava o capitalismo do tipo industrial naquele ínterim: quadro este que se engrandecia perante o conjunto de conhecimentos e saberes concebidos "fundamentais". Esses conhecimentos almejavam um acordo entre o modelamento educacional e as visões de diferentes forças econômicas, políticas e culturais (MALTA, 2013). O que confere sentido a este quadro de conhecimentos e saberes, de acordo com Pacheco (2009) denomina-se teoria de instrução. Para este autor,

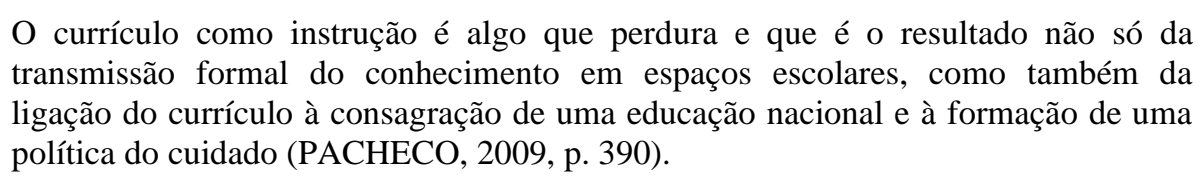

Ao se propor que a teoria da instrução, portanto, confere sentido ao quadro de conhecimentos e saberes "fundamentais" deste período, é possível compreendê-lo enquanto idealização de uma educação nacional transmitida a partir de uma metodologia formal em fomento ao crescimento econômico e industrial norte-americano à época. Este fomento funcionou como mantenedor da possibilidade de promoção social aos indivíduos no interior de um movimento nacional pela escolarização em massa, o que caracterizou a "política do cuidado". Que objetivos, todavia, se extraem desta política senão aqueles orientados pela homogeneidade funcional das aprendizagens? Os objetivos oriundos de uma concepção de conhecimento de ordem disciplinar e de uma escola que motiva, enquanto padrão, a peculiaridade de um indivíduo instruído, educado, vigiado, docilizado, controlado e performativo (PACHECO, 2009).

\footnotetext{
${ }^{1}$ A eugenia, de forma peculiar, impactou fortemente alguns princípios conciliados ao campo educacional, uma vez que o acirramento de conflitos entre grupos raciais se mostrou latejante diante do pressuposto básico deste movimento, em prol da manutenção de uma legitimidade racial (GESSER, 2002).
}

Barbarói, Santa Cruz do Sul, n. 56, p.<282-294>,jan./jun. 2020 
No que tange a Teoria Curricular Tradicional, aos olhos de Silva (2004), existem três nomes a serem destacados: John Dewey ${ }^{2}$, Franklin Bobbit ${ }^{3}$ e Ralph Tyler ${ }^{4}$. Estes três nomes representam as principais influencias curriculares deste momento, tanto acerca de uma formação trabalhista especializada quanto ao fornecimento de subsídios para uma educação em massa à população.

\section{Um direcionamento progressivista do currículo: o modelo Dewey}

Em confronto à lógica do empreendedorismo educacional, Dewey cogitava um raciocínio progressivista acerca do currículo. O que diferencia seu raciocínio dos outros dois pensadores diz respeito ao sobrelevar de seus interesses pela manutenção de uma democracia em relação aos preocupes econômicos. Desta forma, apesar de enlaçado pelos primórdios de um contexto favorável às forças políticas, econômicas e culturais e suas necessidades de garantia hegemônica à ideologia dominante, Dewey preocupava-se demasiado com a disponibilidade de difusão de princípios democráticos ao contexto escolar. Em contrapartida, não mantinha tal demasia para com a preparação de uma vida ocupacional adulta, portanto confrontava a lógica empreendedora caracterizadora do raciocínio de Bobbit (MALTA, 2013).

Gesser (2002) pondera que Dewey, em suas obras, explicitava os pilares fundantes do movimento progressivo. Tendo em vista não ser uma conformidade ao empreendedorismo, mas à manutenção dos ideais democráticos, tal movimento suscitava a importância da experiência e do interesse humano para a constituição da educação. Capacitado a enxergar a escola como uma sociedade em miniatura, o movimento progressivo de Dewey compreendia a cooperação dentro deste ambiente enquanto condição fundamental para o processo de aprendizagem do indivíduo. Este processo, acordado às considerações de Moreira (1990), conduziria ao progresso social, uma vez que, para além da centralidade nas experiências particulares também enfatizaria o conhecimento sistematizado.

\footnotetext{
2 John Dewey (1859-1952) foi um filósofo norte-americano defensor da democracia e liberdade de pensamento como instrumentos para a maturação emocional e intelectual das crianças. No campo pedagógico as ideias deste pensador se inscrevem na chamada educação progressiva.

${ }^{3}$ Franklin Bobbitt (1876-1969): estudioso renomado pela iniciação das teorizações acerca do currículo, entendia este como algo dado para o aluno dentro de uma perspectiva tradicional de ensino. Propôs que a educação deveria seguir os moldes de uma indústria, mas especificamente o molde de organização proposto por Frederick Winsow Taylor.

${ }^{4}$ Ralph Tyler (1902-1994) foi um educador americano que trabalhou na área de análise e avaliação. Sua concepção de aprendizagem assume essencialmente um caráter de controle do planejamento, analogamente ao que ocorre no processo de produção industrial, calcada em pressupostos positivistas.
}

Barbarói, Santa Cruz do Sul, n. 56, p.<282-294>,jan./jun. 2020 
Portanto, vale apreender que a noção de educação progressiva cultivada por Dewey entende ser a escola não uma instituição capacitada à preparação para a vida, mas uma instituição onde ocorre e torna-se transparece o próprio ato de viver. Aranha (2006) evidencia que para Dewey "O fim da educação não é formar a criança de acordo com modelos, nem a orientar para uma formação futura, mas dar condições para que resolva por si própria os problemas" (p. 262), logo há de se perceber que o conhecimento, numa perspectiva progressivista, não tem finalidade em si mesmo, mas volta-se para a noção de experiência. A este ponto Gadotti (2001) soma ainda tornando evidente como a educação acha-se aqui, tãosomente, interpretada como processo e não produto, isto é, um processo de reconstrução e reconstituição de experiências e, conseguintemente, de melhoria da eficiência individual.

\title{
Ordem, racionalidade e eficiência: uma nova racionalidade curricular a partir do tecnicismo de Bobbit
}

Pouco mais de quatro décadas passadas desde as escritas de Dewey, as teorias da administração econômica ${ }^{5}$ passam a influenciar veementemente as concepções curriculares do sistema educacional norte-americano. Este fato se deve, segundo as considerações de Moreira e Silva (2005, p. 10), pelo processo de instauração de

\begin{abstract}
Uma nova concepção de sociedade, baseada em novas práticas e valores derivados do mundo industrial [...]. Cooperação e especialização, ao invés de competição, configuraram os núcleos de uma nova ideologia. $\mathrm{O}$ sucesso na vida profissional passou a requerer evidências de mérito na trajetória escolar. [...] A industrialização e a urbanização da sociedade, então em processo, impossibilitaram a preservação do tipo de vida e da homogeneidade da comunidade rural. Além disso, a presença dos imigrantes nas grandes metrópoles [...] acabou por ameaçar a cultura e os valores da classe média americana [...]. Como consequiência, fez-se necessário e urgente consolidar e promover um projeto nacional comum, assim como restaurar a homogeneidade em desaparecimento e ensinar às crianças dos imigrantes as crenças e os comportamentos dignos de serem adotados.
\end{abstract}

O currículo passa a ser considerado, diante das três urgentes necessidades ponderadas por estes autores, uma massa de manobra para a efetivação do controle social e da adaptação às novidades econômicas, sociais e culturais em vigência. À escola, portanto, coube o ensinamento de condutas, hábitos e valores apropriados, tanto a propósito de reparar a conduta homogênea que vinha se desfalecendo, quanto perspectivando orientações educacionais a partir de um viés econômico, que vinha se fortalecendo. Os princípios fundantes cabíveis a esta vertente tradicional das teorias curriculares, assim sendo, são

\footnotetext{
${ }^{5}$ Especialmente a Teoria da Administração Científica (1903); a Teoria da Burocracia (1909); a Teoria Clássica (Ênfase na Estrutura) (1916); a Teoria das Relações Humanas (1932) e a Teoria Estruturalista (1947).
}

Barbarói, Santa Cruz do Sul, n. 56, p.<282-294>,jan./jun. 2020 
compostos pela forte significância dada à ordem, racionalidade e eficiência (MOREIRA e SILVA, 2005).

Cuchiaro e Carizio (2005) acreditam ainda vigorar, dentro dos espaços de formação, a teoria tradicional do currículo orientada pela eficiência da administração econômica taylorista, caracterizada a partir da instrumentalização de saberes em prol do controle e da ordem social. Para estes autores, a educação confinada a uma ótica tradicionalista compreende uma das mais relevantes armas da classe dominante para manutenção do status quo, para a imposição de pensamentos que confirmem a inercia permanente da estrutura social e, consequentemente, a conjuntura hegemônica da camada dominante.

É justamente esta educação, enquanto potencial mantenedor de uma conjuntura estática, que confere sentido aos arrazoados acerca do princípio tecnicista de Bobbit, segundo o qual a perspectiva curricular deveria girar em torno de um aparato organizacional mecânico e burocrático. Malta (2013) revela que aos olhos de Bobbit os estudos conceituais acerca das perspectivas curriculares deveriam, dentro deste aparato organizacional, compreender três funções: i) o mapeamento de habilidades consistentes aos interesses políticos e ideológicos da época; ii) o desenho de um currículo que sanasse o desenvolvimento de tais habilidades e; iii) a materialização, via instrumentos de mensuração, do quão preciso o currículo se mostrou perante a concretização do desenvolvimento destas habilitações, ditas necessárias.

O princípio tecnicista da perspectiva curricular de Bobbit objetivava fazer com que a escola se sensibilizasse para a eliminação do desperdício. A administração científica orientava tal objetivação a partir do instante em que o ensino se consistia pela eficiência e precisão metodológica, atributos do professor, em detrimento da capacitação das habilidades técnicas dos alunos. Silva (2004, p. 24) considera que o currículo, a partir do princípio tecnicista de Bobbit, seja uma

[...] questão de organização. O currículo é simplesmente uma mecânica. A atividade supostamente científica do especialista em currículo não passa de uma atividade burocrática. [...] o currículo se resume a uma questão de desenvolvimento, a uma questão técnica. O estabelecimento de padrões é tão importante na educação quanto, digamos, numa usina de fabricação de aços, pois, de acordo com Bobbitt, "a educação, tal como a usina de fabricação de aço é um processo de moldagem".

A seus modos, ambas as vertentes comprometidas com a consolidação de uma perspectiva tradicional de escola e currículo buscavam dialogar com todas as modificações políticas, econômicas e sociais atreladas aos EUA durante a primeira metade do século passado (MOREIRA e SILVA, 2005). Gesser (2002) considera que, em meio a este processo, manifestavam-se intelectuais simpatizantes a uma reforma curricular alicerçada pelas ideias 
do movimento reconstrucionista social, caracterizado pela elucidação dos problemas descobertos em ambas as vertentes tradicionais (progressivista e tecnicista).

Pelo comprometimento a uma orientação curricular que, através de soluções da crise social e cultural, perspectivasse a justiça social e, ainda, pela estreita relação estabelecida com as teorias críticas do currículo, que emergem em torno de quatro décadas depois, pode-se inclusive dizer que o movimento reconstrucionista social alavancou a edificação destas teorias.

A relevância das críticas expressas pelo movimento reconstrucionista social, apesar de não romper com a postura tradicional estabelecida para as escolas e para os currículos deste período histórico, faz emergir um sentimento de inquietação a uma parcela de professores, que passam então a enxergar na perspectiva tradicional a percepção de uma desarticulação da totalidade do processo educacional (GESSER, 2002). Desemparelhado da parcela mínima de professores que passaram a estabelecer novos juízos de valor ao direcionamento curricular (movimento reconstrucionista), existia outra parcela atentada à consolidação de novos atributos que conferissem maior organização e desenvolvimento a uma proposta curricular capacitada a combinar propósitos progressivistas aos princípios tecnicistas; é a partir deste vislumbre que se irradia a proposta curricular de Tyler.

\section{A paridade entre o progressivo e o tecnicismo: a proposta técnico-linear de Tyler}

Moreira (1990, p. 67) afirma receber Tyler uma errônea designação no momento em que seu enfoque passa a ser visto como uma "[...] simples repetição dos princípios tecnicistas que influenciaram significativamente o desenvolvimento do pensamento curricular americano na virada do século". Para este autor, portanto, enxergar a vertente curricular proposta por Tyler, impregnada pelo tecnicismo, significa desconsiderar toda uma sequência de procedimentos que estabelecem acentuada relação de similitude, inclusive, às ideias progressivistas, capacitadas a nortear o planejamento, a organização e a avaliação curricular.

Em vista disto Moreira (1990) constata ser ideal uma observação minuciosa acerca da teoria de Tyler, levando em consideração a representação da publicação teórica deste autor enquanto forte influência internacional, até a corrente data, no campo do currículo (GESSER, 2002).

O próprio Tyler (1986, p. 2), no texto introdutório de sua obra, pressupõe que o desenvolvimento curricular se concentra em responder quatro questões centrais, a saber: "Que objetivos educacionais a escola deve procurar atingir? Que experiências educacionais podem ser oferecidas que tenham probabilidade de alcançar esses propósitos? Como organizar essas Barbarói, Santa Cruz do Sul, n. 56, p.<282-294>,jan./jun. 2020 
experiências educacionais de forma eficiente? Como teremos certeza de que esses objetivos estão sendo alcançados?”. Tais questionamentos, diante das análises de Silva (2004), se vinculam respectivamente ao currículo, ensino, instrução e avaliação. Durante as explicitações do primeiro capítulo de sua obra, há três objetivos educacionais fundamentais, que devem ser equitativamente mensurados, quando levados em consideração: i) estudo acerca dos alunos; ii) instrução acerca da vida externa ao contexto educacional e; iii) recomendação advinda de diferentes especialidades (SILVA, 2004).

A partir de seus objetivos educacionais fundamentais, Tyler enxerga nas necessidades e interesses dos alunos uma fonte de contemplação, com isso transpõe o modelo curricular proposto por Bobbit e deixa evidente em sua proposta curricular que, para além de objetivos técnicos, também se orienta por ideais progressivistas. Moreira (1990, p. 62-63) considera que,

Para Tyler, a escola poderia atuar como um agente regulador, que analisaria a
sociedade existente, identificaria falhas, lacunas e necessidades e contribuiria, por
meio de ações individuais, para o progresso social. [...] o desenvolvimento de
atitudes sociais na escola deve ocorrer a partir do uso de um processo de assimilação
do ambiente, através dos efeitos emocionais de certas experiências e através de
processos intelectuais.

A amplitude das ações sociais despertadas pelo ambiente escolar se torna diretamente proporcional ao processo de assimilação ao ambiente. Portanto, a intenção do aluno enquanto comparte ativo às condições externas que lhe cativam e o fazem reagir, somada ao poder do intelecto, é que aguçará uma análise das situações sociais. Consequentemente, suscitará atitudes decisórias em prol de um problema social, de acordo com Moreira (1990), que passa a transcender até mesmo as disciplinas acadêmicas, uma vez que para tal se exige uma interação para além dos seus limites, ou seja, para com a vida externa ao contexto educacional, como menciona o segundo objetivo educacional fundamental.

A crítica imposta sobre Tyler, todavia, se mostra presente ao passo em que sua busca pela resolução dos problemas sociais, a partir da elevação do grau de coerência sobre o ambiente do aluno, passa a evidenciar uma concepção de controle social. Tal concepção, aos olhos de Moreira (1990), apesar de substituir a homogeneização das condutas humanas e o controle burocrático (referência a Bobbit) em prol de uma lógica motivacional individual, se mostra presente diante do fato de Tyler comprometer-se à manutenção do padrão social existente. O progresso social e a qualidade de vida não lançariam mão da moldura liberal influente à sociedade capitalista, portanto, o projeto de transformação social não se desvencilha das novas relações do mundo do trabalho (SANTOS e MACHADO, 2011). 
A este ponto a proposta curricular de Tyler passa a ser uma mescla entre a identificação de ideais progressivistas e a afirmação do controle social, ou seja, diante de um interesse pelo fortalecimento de atitudes sociais, seu modelo (enfaticamente designado como técnico-linear) ainda prevê valores tradicionais. Schmidt (2003), em diálogo à compreensão deste modelo, salienta que sua característica fundante é o domínio do processo pelo especialista em prol da garantia do controle e maximização do rendimento. Os ideais progressivistas de Tyler, portanto, na medida em que se orientam em virtude de uma designação ideal de sociedade (enquanto capitalista e democrática), evidenciam também “[...] uma concepção de controle social que leva em conta os interesses de todos os membros da comunidade" (MOREIRA, 1990, p. 65).

\section{Desfecho: o desfalecimento da perspectiva tradicional do currículo}

Ao narrar os episódios concernentes ao campo do currículo, durante o início do segundo meado do século passado, Gesser (2002) explica que a história possibilita apreender em alguns eventos uma crescente ameaça sobre as concepções curriculares tradicionais. A frente tomada pelos soviéticos em 1957, a partir do lançamento do satélite Sputinik, em plena Guerra Fria é exemplo concreto de tais eventos. Ameaçava-se neste instante o desenvolvimento tecnológico e científico dos EUA e, consequentemente, o caráter curricular atribuído ao sistema educacional deste país.

\footnotetext{
[...] os americanos culparam os educadores, principalmente os progressivistas, pelo que julgaram ser uma derrota na corrida espacial. Insistiram, então, na necessidade de se reestruturar a supostamente perdida qualidade da escola. Novos programas, materiais, estratégias e propostas de treinamento de professores foram elaborados e implementados. A intenção mais ampla, subjacente aos esforços, era enfatizar a redescoberta, a investigação e o pensamento indutivo [...] (MOREIRA e SILVA, p. 12 e 13, 2005).
}

Toda ênfase dada à reformulação da estrutura educacional não foi o suficiente para confrontar os problemas que passaram a ser fertilizados dentro da sociedade norte-americana. A consolidação de uma democracia pautada pelo ideário justo e humano tornava-se cada vez mais utópica, uma constante revolta acerca dos valores tradicionais embutidos ao aparato educacional fundiu-se ao sentimento de vergonha perante a incapacidade de se estabelecer medidas justas para a resolução de uma série de problemas que afetavam as relações sociais àquele momento no país, como o racismo, desemprego, crime, moradia e violência urbana.

A tese de Schwab e Harper (1970) compreende, neste ínterim, a morte do currículo enquanto campo de estudo, uma vez que sustenta, em primeira instância, não haver métodos e princípios capacitados a enxergar a variedade de problemas emergentes sob uma nova ótica. 
Essa premissa viabilizaria uma contribuição significativa do avanço educacional. Entretanto a realidade que se mostra na crítica destes autores justifica um campo curricular infestado pela infelicidade e criminado mediante exagerada confiança, depositada pelo sistema educacional em princípios dedutivos capacitados a designar procedimentos ditos "adequados" diante a extrema necessidade de reformulação de conceitos curriculares, depois das ameaças feitas às tendências tradicionais.

A reformulação de tais conceitos, assim como a emersão deste campo curricular caracterizado pela tentativa de retificação das irregularidades propostas nos discursos tradicionais, fez alastrar um sentimento de crise à sociedade norte-americana, que diante de tal conjuntura acaba por reformular a acepção e os valores dados à vida.

Moreira e Silva (2005, p. 13), ao fazerem jus a tal reformulação, destacam a propagação de “[...] uma contracultura que enfatizava prazeres sensuais, liberdade sexual, gratificação imediata, naturalismo, uso de drogas, vida comunitária, paz e libertação individual". Com o emergir desta contracultura, assim como com a confiança depositada em sua acepção e valores, as instituições educacionais passaram a sofrer ferrenhas críticas no concernente a uma instrução social fidedigna às perspectivas curriculares tradicionais.

Colocam em xeque os movimentos devotados à contracultura, ou seja, o quão a instrução social das escolas não apontava para o nível pretendido de ascensão. Em defesa desta incriminação, e perspectivando tanto uma transformação quanto uma democratização das instituições de ensino, tais movimentos acusavam a escola de ser demasiadamente tradicional, opressiva, castradora, violenta e irrelevante (MOREIRA e SILVA, 2005).

Silva (2004) considera ainda à década de 1960, para além da emersão da contracultura, uma série de outros movimentos sociais e culturais (para além da realidade norte-americana inclusive) que, ao se rebelarem, tornaram-se artífices ao processo de teorização de uma nova lógica para se pensar a estrutura das instituições educacionais. Assim menciona este autor os movimentos que merecem destaque:

Os movimentos de independência das antigas colônias européias; os protestos estudantis na França e em vários outros países; a continuação do movimento dos direitos civis nos Estados Unidos; os protestos contra a guerra do Vietnã; os movimentos de contracultura; o movimento feminista; a liberação sexual; as lutas contra a ditadura militar no Brasil (SILVA, 2004, p. 29).

A ênfase internacional dada aos movimentos sociais e culturais viabiliza notar a perspectiva curricular tradicional sendo intimada a partir de diferentes países ao mesmo tempo. Ao que concerne a conjuntura norte-americana, que vem sendo utilizada neste estudo como ferramenta para a compreensão do aparato histórico que subsidia a perspectiva 
tradicional de currículo, há destaque: i) ao movimento reconceitualista; ii) a reparação dos escombros motivados pelas teorias tradicionais do currículo, em contexto britânico, se relaciona à "nova sociologia da educação"; iii) em solo brasileiro há de se assinalar os pressupostos freireanos; iv) o contexto francês também merece destaque perante a ampla repercussão contida na literatura de Althusser, Bourdieu e Passeron e Baudelot e Establet (SILVA, 2004).

Dentre os movimentos expressos acima, aqueles atrelados ao contexto brasileiro, britânico e francês, se identificam pela formulação de uma teoria educacional crítica (e supostamente uma influência desta à perspectiva curricular que viria a se desabrochar) não tendenciosa ao campo pedagógico e educacional, portanto muito vinculados às vertentes sociológicas e filosóficas. Em compasso a estes movimentos, os pressupostos de Paulo Freire em "A Pedagogia do Oprimido", a "Nova Sociologia da Educação" britânica e os ensaios de Althusser e Bourdieu em colaboração com Passeron respectivamente em "A Ideologia e os Aparelhos Ideológicos do Estado" e "A Reprodução", se configuram enquanto parte da mola propulsora das perspectivas curriculares críticas que se vinculam ao outro contexto anteriormente destacado.

Em contrapartida, o movimento de reconceptualização norte-americano distingue-se dos demais por sua forte tendência ao campo de estudo pedagógico e educacional. Este entendimento torna-se o ponto de partida para a compreensão da eclosão das teorizações críticas, sobretudo caracterizadas ao contexto brasileiro e francês e, consequentemente, de teorizações críticas curriculares, segundo grupo de teorias curriculares alusivo aos estudos de Silva (2004) que merece, seguramente, ser alvo de uma investigação posterior.

\section{REMINISCENCIAS DE LA TEORÍA TRADICIONAL DEL CURRÍCULO: UN MAPEO DE LA CONJUNCIÓN NORTEAMERICANA SOBRE EL INAUGURAR DEL SIGLO XX}

\section{Resumen}

Este estudio se caracteriza como una investigación bibliográfica objetivada a comprender el sentido dado a la dinámica curricular a partir de los matices socio-político-culturales que se protagonizaron en los Estados Unidos de América durante el primer mediado del siglo pasado. Se configura en cinco tópicos consecuentes, a partir de un espectro histórico, que

\footnotetext{
${ }^{6}$ Silva (2004) entende esse movimento enquanto o ponto auge reivindicatório da literatura inglesa, em especial das publicações de Michael Young, em prol de uma nova concepção de currículo. Este movimento data-se a partir da publicação do livro "Knowledge and Control" no ano de 1971. Diferentemente dos norte-americanos, que tinham como aporte teórico as Teorias Tradicionais do Currículo, os ingleses se respaldavam na "antiga" Sociologia da Educação para elaborar suas reflexões acerca da materialização de uma concepção curricular crítica.
} 
discurren desde el proceso de institucionalización de la educación masiva, fomentador del surgimiento de la Teoría Curricular Tradicional (primordios del siglo pasado), hasta el momento de crisis de la propuesta curricular de Tyler (mediados del siglo XX). También es objeto de especulación de este estudio, en el curso del trayecto histórico considerado, evidenciar las contribuciones de Dewey y Bobbit frente a la Teoría Tradicional del Currículo. El esfuerzo de síntesis sobre el desfase de esta perspectiva curricular frente a la necesidad humana por la reconfiguración del abarrotado escenario educativo norteamericano. Palabras clave: Historia del currículo; teoría curricular; pedagogía tradicional.

\title{
CURRICULUM TRADITIONAL THEORY REMINISCENCES: NORTH AMERICAN CONJECTURE MAPPING ON THE 20TH CENTURY INAUGURATION
}

\begin{abstract}
This study is characterized as a bibliographical research aimed at understanding the meaning given to curricular dynamics from the socio-political-cultural nuances that perform a key role in the United States of America during the last century first half. It is based on five sequential topics that range from the institutionalization process of mass education, fomenting the Traditional Curricular Theory emergence (early in the last century), until the Tyler curricular proposal crisis (mid twentieth century). It is also speculation in this study, during the historical course considered, to highlight the Dewey and Bobbit contributions to the Traditional Theory of Curriculum. The synthesis effort hovers on the fading of this curricular perspective in front of the human need for the educational scene North American reconfiguration.
\end{abstract}

Keywords: Curriculum history; curricular theory; traditional pedagogy.

\section{REFERÊNCIAS}

ARANHA, Maria Lúcia de Arruda. História da educação e da pedagogia: geral e Brasil. 3. ed. São Paulo: Moderna, 2006.

CUCHIARO, André Luiz; CARIZIO, Walkiria Graick. Ensino superior, currículo e formação profissional. Revista Fafibe Online, Bebedouro, v. 1, n. 1, n.p., 2005. Disponível em: http://www.unifafibe.com.br/revistasonline/arquivos/revistafafibeonline/sumario/9/18052011 155059.pdf. Acesso em: 22 out. 2019.

GADOTTI, Moacir. História das idéias pedagógicas. 8. ed. São Paulo: Editora Ática, 2001.

GESSER, Verônica. A evolução histórica do currículo: dos primórdios à atualidade.

Contrapontos, Itajaí, v. 2, n. 4, p. 69-81, jan./abr. 2002.

LIMA, Telma Cristiane Sasso de; MIOTO, Regina Célia Tamaso. Procedimentos metodológicos na construção do conhecimento científico: a pesquisa bibliográfica. Revista Katálysis, Florianópolis, v. 10. n. esp. p. 37-45, 2007.

MALTA, Shirley Cristina Lacerda. Uma abordagem sobre currículo e teorias afins visando à compreensão e mudança. Espaço do Currículo, João Pessoa, v. 6, n. 2, p. 340-354, mai./ago. 2013. 
MOREIRA, Antonio Flavio Barbosa. Currículos e programas no Brasil. 10. ed. Campinas: Papirus, 1990.

MOREIRA, Antonio Flavio Barbosa; SILVA, Tomaz Tadeu da. Sociologia e Teoria Crítica do Currículo: uma introdução. In: MOREIRA, Antonio Flavio Barbosa; SILVA, Tomaz Tadeu da. (Orgs). Currículo, Cultura e Sociedade. 8. ed. São Paulo: Cortez, 2005, p. 7-38.

PACHECO, José Augusto. Currículo: entre teorias e métodos. Cadernos de Pesquisa, São Paulo, v.39, n. 137, p. 383-400, mai./ago. 2009.

SANTOS, Luan Bergston; MACHADO, Liliane Campos. O currículo: teoria, história e prática docente. In: CONGRESSO NORTE-MINEIRO DE PESQUISA EM EDUCAÇÃO, 3., 2011, Montes Claros. Anais [...]. Montes Claros, UNIMONTES, n.p. 2011.

SCHMIDT, Elizabeth Silveira. Currículo: uma abordagem conceitual e histórica. Publicatio UEPG: Ciências Humanas, Linguistica, Letras e Artes, Ponta Grossa, v. 11, n. 1, p. 59-69, jun. 2003.

SCHWAB, Joseph Jackson; HARPER, William Rainey. The practical: a language for curriculum. New York: Ford Foundation, 1970. 44 p.

SILVA, Maria Aparecida da. História do currículo e currículo como construção históricocultural. In: VI Congresso luso-brasileiro de História da Educação, 2006, Uberlândia. Anais [...]. Uberlândia: EDUFU, v. 1. p. 4820-4828, 2006.

SILVA, Tomaz Tadeu da. Documentos de identidade: uma introdução às teorias do currículo. 2. ed. Belo Horizonte: Autêntica, 2004.

TYLER, Ralph Winfred. Principios básicos del currículo. 5. ed. Buenos Aires: Editorial Troquel, 1986.

Data de recebimento: $12 / 02 / 2020$

Data de aceite: $21 / 05 / 2020$

\section{Sobre o autor:}

Júlio César Apolinário Maia é Licenciado em Educação Física pela Universidade Estadual de Goiás - Campus Goiânia ESEFFEGO (UEG-ESEFFEGO). Mestrando em Educação pela linha de pesquisa Formação Humana e Fundamentos da Educação do Programa de PósGraduação em Educação da Universidade Federal de Jataí (UFJ). Endereço Eletrônico: jcesarm@outlook.com 